\title{
British Intestinal Failure Alliance (BIFA) guidance - haematological and biochemical monitoring of adult patients receiving home parenteral nutrition
}

\section{Gavin William Mercer-Smith (D) , ${ }^{1}$ Colette Kirk ${ }^{2}$ Lisa Gemmell, ${ }^{2}$ Christopher Mountford, ${ }^{3}$ Jeremy Nightingale, ${ }^{4}$ Nick Thompson ${ }^{3}$}

\begin{abstract}
'Blood Sciences, Newcastle upon Tyne Hospitals Department of Laboratory Medicine, Newcastle upon Tyne, UK

${ }^{2}$ Nutrition - Newcastle Hospitals, Newcastle Upon Tyne Hospitals NHS Foundation Trust, Newcastle Upon Tyne, UK

${ }^{3}$ Gastroenterology, Newcastle Upon Tyne Hospitals NHS Foundation Trust, Newcastle Upon Tyne, UK

${ }^{4}$ Gastroenterology, London North West University Healthcare NHS Trust, Harrow, UK
\end{abstract}

\section{Correspondence to}

Dr Gavin William Mercer-Smith, Blood sciences, Newcastle upon Tyne Hospitals Department of Laboratory Medicine, Newcastle upon Tyne NE1 4LP, UK; gavin. mercer-smith@nhs.net

Received 11 December 2020

Revised 12 January 2021

Accepted 17 January 2021

Published Online First

1 February 2021

\section{Check for updates}

(c) Author(s) (or their employer(s)) 2021. No commercial re-use. See rights and permissions. Published by BMJ.

To cite: Mercer-Smith GW, Kirk C, Gemmell L, et al. Frontline Gastroenterology 2021;12:656-663.

\section{ABSTRACT}

Home parenteral nutrition (HPN) is necessary

for patients with prolonged intestinal

failure which can be secondary to a variety

of pathophysiological mechanisms or surgical resection. HPN is needed to supply micronutrients, macronutrients and water to reduce morbidity and mortality and to maximise the patient's quality of life.

HPN requires close monitoring by a dedicated multidisciplinary team and is vital to minimise complications; both catheter related and metabolic. A regular comprehensive review is required including history, examination including anthropometry and blood testing. The focus of this review is on the monitoring of haematological and biochemical parameters.

There is a paucity of evidence-based literature on the biochemical monitoring of HPN and existing guidance is sourced mostly on expert opinion and lower grade studies. Sources offering guidance on the frequency of biochemical monitoring for the stable adult HPN patient are the British Association for Parenteral and Enteral Nutrition, the European Society for Parenteral and Enteral Nutrition, the National Institute for Health and Care Excellence and the Australasian Society of Parenteral and Enteral Nutrition (AUSPEN).

The aim of this work is to review and collate this existing guidance into one clear and concise review. It is recommended that biochemical parameters are checked at baseline, thereafter more frequently if concerns arise and less frequently when the patient's condition is stable, as assessed by the multidisciplinary team with expertise in HPN.

\section{BACKGROUND}

The essential components of a diet/feed are macronutrients (carbohydrate, fat and protein), water, minerals (includes those often referred to as electrolytes $(\mathrm{Na}, \mathrm{K}$, $\mathrm{Cl}, \mathrm{HCO} 3, \mathrm{Ca}, \mathrm{Mg}, \mathrm{P}$ ), trace elements (eg $\mathrm{Cu}, \mathrm{Zn}, \mathrm{Mn}$ and SE) and vitamins (water and fat soluble). The macronutrient status is mainly monitored by a clinical examination (weight, body mass index, muscle mass) though lipid is also measured in the blood. Liver, kidney and bone/haematological functions, in addition to mineral and vitamin status can be assessed from blood tests. This document relates to adult patients having parenteral nutrition (HPN) at home though may be used for those also having parenteral fluid.

There is a scarcity of evidence-based literature on monitoring in HPN and recommendations are based mostly on expert opinion. Monitoring, which is the responsibility of a multidisciplinary team with expertise in HPN, is crucial in order to maximise the benefits of HPN, to prevent and treat complications, and to secure and improve the quality of life (QoL) of the patient. We have assumed that patients going home are stable and not at risk of refeeding problems. Wengler et al studied monitoring practices for HPN across Europe and concluded that the majority of centres monitored stable HPN patients at 3 monthly intervals. ${ }^{1}$ In the future, more remote monitoring of patients is likely to be required to reduce the need for patients to travel to an HPN centre or an integrated intestinal failure centre, especially due to concerns about 
BIFA recommendations

1. All haematological and biochemical monitoring of HPN patients should be individualised and may change with their clinical condition. The point at which patients become stable post discharge will vary.

2. Routine blood tests, including standard electrolytes, chloride, bicarbonate (as a measure of acid-base balance), calcium, magnesium, phosphate, renal and liver function tests, glucose, full blood count, ferritin and CRP should be performed monthly for the first 3 months after discharge. If stable this may then be 3-4 monthly.

3. When discharged patients should have their prothrombin time, cholesterol and triglyceride, haemoglobin A1c (HbA1c), vitamin D and $B_{12}$ and folate concentrations checked. These should then be monitored at least 6 monthly.

4. Patients who are to receive long-term HPN should have baseline vitamins A and E, zinc, copper, manganese and selenium concentrations checked and then monitored 6-monthly.

5. If the CRP is significantly raised ( $>20 \mathrm{mg} / \mathrm{L})$ iron can be measured with transferrin and transferrin saturation to assist interpretation of iron status. In this situation, care must be taken in the interpretation of zinc, copper, selenium and vitamins A, D and E in view of their inflammatory response.

6. When measuring zinc, copper, manganese or selenium use a trace element-free collection tube.

7. If the triglyceride concentration is elevated a fasting concentration should be repeated.

8. Urine sodium concentration is useful for assessing sodium balance in patients with a short bowel and a 24-hour urinary oxalate collection for assessing risk of renal stone formation in patients with a short bowel and colon in continuity.

BIFA, British Intestinal Failure Alliance; CRP, C-reactive protein; HPN, home parenteral nutrition.

SARS-CoV-2 infection risk. Frequency of hospital visits and accessibility of micronutrient testing is likely to be reduced due to SARS-CoV-2 restrictions and it may be possible for 3 monthly blood tests to be taken within primary care with the less stable vitamins and trace elements sampled at 6 monthly face-to-face hospital visits. It is, therefore, important that monitoring protocols are clear, safe but not burdensome. Key recommendations from our review are listed in table 1.

\section{Summaries of recommendations from National Institute for Health and Care Excellence, British Association for Parenteral and Enteral Nutrition and European Society for Parenteral and Enteral Nutrition guidelines}

National Institute for Health and Care Excellence (NICE) guidelines (2006/2017)

National Institute for Health and Care Excellence (NICE)guidelines (2006/2017) for nutrition support for adults: oral support, enteral tube feeding and parenteral nutrition (CG 32), February 2006, revised August $2017 .^{2}$ 'People in the community having parenteral nutrition ... should receive an individualised care plan which includes ... a monitoring plan.' Patients should be reviewed by appropriately skilled teams at a specialist hospital clinic every 3-6 months. Monitoring should be more frequent during the early months of home parenteral nutrition, or if there is a change in clinical condition.

Zinc, copper, folate and $\mathrm{B}_{12}$ should be checked at baseline and thereafter every 2-4 weeks, however, it is not clear what the interval should be for those at home. Selenium at baseline and then dependent on concentrations and if suspected deficiency (glutathione peroxidase is a preferred test if available). Iron and ferritin at baseline and then every 3-6 months. Manganese every 3-6 months and vitamin D every 6 months.
British Association for Parenteral and Enteral Nutrition (BAPEN) guidelines (2016)

These guidelines suggest that stable patients are monitored between monthly and 3 monthly, depending on the patient's condition. Electrolytes (sodium, potassium and magnesium), bone profile (calcium and phosphate), infection markers (such as $\mathrm{C}$ reactive protein (CRP) and white blood cells) and liver function tests should be taken at baseline and then at each planned follow-up. Cholesterol and triglycerides may be reviewed weekly initially, reducing to 3 monthly once stable to monitor the risk of potential hyperlipidaemia.

Trace elements (zinc, copper, selenium and manganese) and vitamins (A, D, E, $B_{12}$ and folate) should be checked at baseline if there is previous evidence of malnutrition. This should then be repeated 3 monthly in long-term patients to detect deficiencies or raised concentrations. It is important to interpret these results with caution and monitor clinical symptoms, as serum concentrations can be reduced or raised when inflammatory markers are raised during the acute phase response, and may not reflect total body stores.

European Society for Parenteral and Enteral Nutrition (ESPEN) guidelines (2020)

Monitoring should be more frequent during the early months of HPN, or if there is a change in the patient's clinical condition. In clinically stable patients on longterm HPN haematology and biochemistry (haemoglobin, ferritin, albumin, CRP, electrolytes, venous blood gas analysis, kidney function, liver function and glucose) should be measured at all scheduled reviews (eg, every 3-6 months). In patients on long-term HPN, clinical signs and symptoms as well as biochemical indexes of vitamin and trace metal deficiency or toxicity should be evaluated at least once per year. Vitamin and trace metal deficiency may take more time to develop and to present clinical signs and symptoms, so that an interval 
assessment of 6-12 months is appropriate. Prospective studies of the impact of different monitoring regimens on outcomes (including QoL) of HPN are warranted.

Baseline tests should be include full blood count, CRP, glucose, sodium, potassium, chloride, bicarbonate, magnesium, phosphate, calcium and renal function tests including urea and creatinine. Measurements should be weekly or monthly until stable and then performed regularly. Once stability has been achieved, this might be 3-4 monthly.

Liver function tests, including INR and albumin, should be measured monthly and can be reduced to 3-4 monthly when stable. Serum iron and ferritin should be measured every 3-6 months with other micronutrients every 6-12 months (zinc, selenium, copper, vitamins A, E, D, $B_{12}$ and folic acid). Serum manganese should be checked annually.

\section{Commercial micronutrient preparations}

In general, micronutrients for HPN patients are provided in the form of fixed combinations within multivitamin or multitrace element solutions. This restricts prescribing options and makes it difficult to adjust the dose of individual micronutrients. Numerous observational studies and case reports have identified high concentrations of manganese, copper and chromium in patients receiving HPN, likely due to contamination of $\mathrm{PN}$ products, and low concentrations of selenium and zinc. ${ }^{34}$

\section{Effect of inflammatory response on micronutrient status}

During the acute phase response, quantified by measuring CRP, serum concentrations of iron, zinc, selenium and vitamin A decrease and copper and ferritin concentrations increase. ${ }^{5}$ These alterations in concentrations likely represent redistribution rather than true deficiency and this may actually be a beneficial and adaptive response. For example, reduced concentrations deprive micro-organisms of vitamins and trace elements essential for growth and replication, and limits free radical production. During the resolution phase of sepsis, serum concentrations return to previous concentrations. The interpretation of zinc requires additional consideration as $90 \%$ of zinc is bound to albumin and concentrations will therefore be reduced when albumin decreases.

Micronutrients such as vitamins $B_{12}$ and folate appear unaffected by the inflammatory response and therefore low concentrations are likely to represent true nutritional deficiencies. Further research is needed to examine the inter-relationships between the inflammatory response and circulating concentrations of vitamins $\mathrm{C}, \mathrm{D}$ and $\mathrm{E}$.

\section{METHODOLOGY AND LIMITATIONS OF THESE RECOMMENDATIONS}

There is a paucity of research in the area of monitoring in HPN, particularly around micronutrient monitoring, much of the available evidence is based on lower-grade studies/poor-quality studies. Scoping of studies published in Medline (Ovid) and EMBASE was conducted with no restrictions on dates, however, limits to 'Humans' and 'English Language' were applied. A combination of key terms was used: parenteral nutrition *, intestinal failure *, vitamin*, retinol, tocopherol *, zinc, copper, selenium*, micronutrient* and trace element*. No studies were found looking at monitoring or replacing vitamin A or E, zinc, copper or selenium in stable patients being treated with home parenteral nutrition, demonstrating the sparsity of research within this patient group. We reviewed current guidance from relevant national and international organisations. This document was circulated to all members of the British Intestinal Failure Alliance committee and we are very grateful for their comments.

\section{OVERVIEW OF MEASUREMENTS}

For a summary of the suggested monitoring frequency for all measurements listed below please see table 2 and for a summary by source of recommendation please see table 3 .

\section{Standard electrolytes and urea and creatinine Sodium}

Standard laboratory methods can be subject to pseudohyponatraemia due to the electrolyte exclusion effect which can be caused by severe hyperproteinaemia and hyperlipidaemia-in these cases alternative methodology is recommended and should be discussed with the laboratory. There is a need to interpret with knowledge of fluid status-sodium is closely linked to water homoeostasis and changes in extracellular water volume will cause a change in sodium concentration. ${ }^{6}$ Urinary sodium (and chloride) can be used to aid in detecting a salt-retaining state with concentrations $<20 \mathrm{mmol} / \mathrm{L}$ indicating this, however concentrations above this do not exclude hypovolaemia. ${ }^{7}$

\section{Potassium}

To avoid spurious hyperkalaemia avoid delays in separation, fist clenching and can result from haematological conditions such as thrombocytosis and leucocytosis (suggest use lithium heparin tube if this is a concern).

\section{Chloride}

Generally increases or decreases in direct relationship to sodium, but may change without any change in sodium when there are disturbances of acid-base balance. $^{6}$

\section{Bicarbonate (total carbon dioxide)}

Dissolved carbon dioxide in the sample will escape into the air over time causing a decrease in the result, however, in a normal serum sample the stability of bicarbonate is 16 hours. $^{8}$ If there is concern about acidbase balance then an arterial blood gas may provide 
Table 2 Haematological and biochemical monitoring of patient having HPN and considered clinically stable

\begin{tabular}{|c|c|c|c|}
\hline & 3-4 monthly & 6 monthly & Annually \\
\hline Blood count & $x$ & & \\
\hline Prothrombin time (INR) & & $x$ & \\
\hline $\begin{array}{l}\text { Renal function* } \\
\text { ( } \mathrm{Na}, \mathrm{K}, \mathrm{Cl}, \mathrm{HCO} 3 \text {, urea, creatinine) }\end{array}$ & $x$ & & \\
\hline CRP & $x$ & & \\
\hline $\begin{array}{l}\text { Liver function } \\
\text { (Alk P, GGT, ALT, AST, Bil, T prot, albumin) }\end{array}$ & $x$ & & \\
\hline Bone chemistry (Mg, Ca, P) & $\mathrm{x}$ & & \\
\hline Glucose/HbA1c & $x$ & & \\
\hline Cholesterol and triglyceride & & $x$ & \\
\hline Vitamins (A, D, E, $B_{12^{\prime}}$ folate) $\dagger$ & & $\mathrm{x}$ & \\
\hline Ferritin/Fe/TIBC & & $x$ & \\
\hline Trace elements (Zn, Cu, Se, Mn) & & $x$ & \\
\hline Urinary $\mathrm{Na}^{*}$ & $x$ & & \\
\hline 24 hours urine oxalate (J-C patients only) & & & $x$ \\
\hline Thyroid function tests, TSH & & & $x$ \\
\hline
\end{tabular}

These are suggested time intervals for stable patients. If the results are abnormal or the clinical situation changes they may be done more frequently. Chromium and vitamin C/other B vitamins are not routinely measured in the UK.

* $\mathrm{HCO}$, chloride and urinary $\mathrm{Na}$ if stable may be done annually.

†Vitamins $\mathrm{A}$ and $\mathrm{E}$ may be measured annually unless results are abnormal.

ALT, alanine aminotransferase; AST, aspartate aminotransferase; CRP, C reactive protein; GGT, gamma-glutamyltransferase; HPN, home parenteral

nutrition; TIBC, total iron binding capacity; TSH, thyroid stimulating hormone.

more information however this is more invasive, requires immediate analysis and is rarely performed.

\section{Calcium}

Sample should ideally be taken without the use of a tourniquet. ${ }^{6}$ Assay detects total serum calcium; free (unbound) calcium can be measured using point of care analyser (direct ion selective electrode). The calculation for adjusted calcium is invalid when albumin $<20 \mathrm{~g} / \mathrm{L}$, in these cases, direct measurement of free calcium can be performed using a blood gas analyser.

\section{Phosphate}

There is a risk of hypophosphataemia from some intravenous iron infusions; it is proposed that intravenous iron mediates an increase of serum fibroblast growth factor 23 which is phosphaturic. ${ }^{9}$

\section{Magnesium}

Detects total serum magnesium.

Urea

Gives an indication of protein (nitrogen) intake (dietary or parenterally) in addition to renal function. As a general test of renal function urea is of limited value-creatinine (which relates to muscle mass) and estimated glomerular filtration rate (eGFR) is preferable. It can be difficult to ascribe a cause to abnormal urea concentrations as they are affected by rate of synthesis (protein turnover), volume of distribution (hydration status) and rate of excretion-urea tends to rise before creatinine in early pre-renal failure.
Creatinine

Superior to urea as a test of general renal function, serum creatinine concentration can be used together with demographic information to calculate the eGFR, wide normal reference interval due to large interindividual variation. High muscle mass can cause slightly elevated creatinine concentrations in those with normal renal function.

Bilirubin (total)

Clinically jaundice tends to become apparent when bilirubin is $>3 \mathrm{x}$ upper limit of normal.

Glucose

If considering a diagnosis of diabetes mellitus this is either by measurement of $\mathrm{HbA} 1 \mathrm{c}$ or oral glucose tolerance testing as per WHO guidelines.

Suggested monitoring frequency:

- BAPEN-1-3 monthly. ${ }^{10}$

- NICE-guidance offers no distinction between inpatient/outpatient setting. ${ }^{2}$

- ESPEN (2020)-weekly or monthly, 3-4 monthly when stable. ${ }^{11}$

- AuSPEN—3 monthly. ${ }^{12}$

\section{Liver enzymes}

Alanine aminotransferase and aspartate aminotransferase

In fatty liver disease, an activity ratio aspartate aminotransferase (AST)/alanine aminotransferase (ALT) of $>2$ suggests alcohol as a cause; a ratio of $\leq 1$ is suggestive of a non-alcoholic cause. ${ }^{6}$ ALT is 
Table 3 Suggested monitoring frequency per source of recommendation

\begin{tabular}{|c|c|c|c|c|}
\hline Analyte & BAPEN $^{10}$ & $\mathrm{NICE}^{2}$ & ESPEN $^{11}$ & AUSPEN ${ }^{12}$ \\
\hline $\begin{array}{l}\text { Sodium, potassium, chloride, } \\
\text { bicarbonate, calcium, } \\
\text { phosphate, magnesium, } \\
\text { urea, creatinine, bilirubin } \\
\text { and glucose }\end{array}$ & 1-3 monthly & $\begin{array}{l}\text { Guidance offers no distinction } \\
\text { between inpatient/outpatient } \\
\text { setting }\end{array}$ & $\begin{array}{l}\text { Weekly or monthly, 3-4 } \\
\text { monthly when stable }\end{array}$ & 3 monthly \\
\hline Liver enzymes & As above & As above & $\begin{array}{l}\text { Monthly, 3-4 monthly } \\
\text { when stable }\end{array}$ & As above \\
\hline Total protein and albumin & $\begin{array}{l}\text { As above } \\
\text { (assumed as part of 'liver } \\
\text { function tests') }\end{array}$ & Not given & As above & $\begin{array}{l}\text { As above } \\
\text { (assumed as part of 'liver } \\
\text { function tests') }\end{array}$ \\
\hline CRP & As above & $\begin{array}{l}\text { Guidance offers no distinction } \\
\text { between inpatient/outpatient } \\
\text { setting }\end{array}$ & $\begin{array}{l}\text { Weekly or monthly, 3-4 } \\
\text { monthly when stable }\end{array}$ & $\begin{array}{l}\text { 'Inflammatory markers } \\
\text { if ongoing inflammatory } \\
\text { disease-no frequency given }\end{array}$ \\
\hline Full blood count and PT & $\begin{array}{l}\text { White cell count } 1-3 \\
\text { monthly, no mention of PT }\end{array}$ & $\begin{array}{l}\text { Full blood count and mean cell } \\
\text { volume-guidance offers no } \\
\text { distinction between inpatient/ } \\
\text { outpatient setting }\end{array}$ & As above & $\begin{array}{l}\text { 'Haematology screen' } \\
3 \text { monthly, with INR if } \\
\text { anticoagulated }\end{array}$ \\
\hline $\begin{array}{l}\text { Lipids: cholesterol and } \\
\text { triglycerides }\end{array}$ & 3 monthly & Not given & Not given & $\begin{array}{l}\text { 'Longer-term patients should } \\
\text { have a lipid screening'—no } \\
\text { frequency given }\end{array}$ \\
\hline Vitamin D* & As above & 6 monthly & Every 6-12 months & Not given \\
\hline Vitamin $\mathrm{B}_{9}$ and $\mathrm{B}_{12}$ & As above & $\begin{array}{l}\text { Guidance offers no distinction } \\
\text { between inpatient/outpatient } \\
\text { setting }\end{array}$ & As above & Not given \\
\hline Vitamin $\mathrm{A}$ and $\mathrm{E}$ & As above & Not given & As above & Not given \\
\hline Iron and ferritin & Not given & 3-6 monthly† & Every 3-6 months & 'Iron status' 6 monthly \\
\hline Copper and zinc & 3 monthly & $\begin{array}{l}\text { Guidance offers no distinction } \\
\text { between inpatient/outpatient } \\
\text { setting }\end{array}$ & Every 6-12 months & 6 monthly \\
\hline Manganese & As above & 3-6 monthly & Annually & As above \\
\hline Selenium & As above & $\begin{array}{l}\text { 'Further testing dependent on } \\
\text { baseline' }\end{array}$ & Every 6-12 months & As above \\
\hline
\end{tabular}

${ }^{*}$ Association for Clinical Biochemistry (ACB) -Repeat after 3-6 months on replacement if baseline was low and potential absorption defect. ${ }^{20}$ †ACB - Also endorsed by the ACB national minimum re-testing interval project. ${ }^{20}$

BAPEN, British Association for Parenteral and Enteral Nutrition; CRP, C reactive protein; ESPEN, European Society for Parenteral and Enteral Nutrition;

NICE, National Institute for Health and Care Excellence; PT, prothrombin time.

preferred over AST as an indicator of liver cell damage as it is more specific. ${ }^{6}$

\section{Alkaline phosphatase}

Alkaline phosphatase (ALP) is approximately equally of hepatobiliary and bone origin; other sources are small intestine, placenta and kidney. ${ }^{6}$ To investigate the source of elevated ALP, adding gamma-glutamyltransferase (GGT) can help to distinguish hepatobiliary origin or with an isolated ALP elevation-serum electrophoresis distinguishes ALP isoenzymes.

\section{Gamma-glutamyltransferase}

GGT can be used to indicate hepatic origin of elevated serum ALP activity, and can suggest compliance with abstinence in patients with alcohol-related liver disease. $^{6}$

Suggested monitoring frequency:

- BAPEN-1-3 monthly. ${ }^{10}$
- NICE-guidance offers no distinction between inpatient/outpatient setting. ${ }^{2}$

- ESPEN (2020)—monthly, 3-4 monthly when stable. ${ }^{11}$

- AuSPEN-3 monthly. ${ }^{12}$

\section{Proteins}

Total protein and albumin

In inflammatory states concentration of albumin decreases but immunoglobulins increase. Albumin is a poor guide to nutritional status. ${ }^{6}$ High or low-albumin concentrations are frequently multifactorial, with more than one mechanism being responsible for example, hydration status, inflammation, hepatic impairment. Used in the interpretation of adjusted calcium concentration. Total protein $=$ albumin + globulin, the major component of globulin component is immunoglobulins. Suggested monitoring frequency:

- BAPEN (assumed as part of 'liver function tests') -1-3 monthly. ${ }^{10}$ 
- NICE-not given. ${ }^{2}$

- ESPEN (2020)-monthly, 3-4 monthly when stable. ${ }^{11}$

- AuSPEN (assumed as part of 'liver function tests')-3 monthly. ${ }^{12}$

C- reactive protein

concentration increases with inflammation and so assists interpretation of protein, trace element and vitamin results. ${ }^{2}$ Suggested monitoring frequency:

- BAPEN-1-3 monthly. ${ }^{10}$

- NICE-guidance offers no distinction between inpatient/outpatient setting. ${ }^{2}$

- ESPEN (2020)—weekly or monthly, 3-4 monthly when stable. $^{11}$

- AuSPEN- 'Inflammatory markers if ongoing inflammatory disease'-no frequency given. ${ }^{12}$

\section{Full blood count and prothrombin time}

Full blood count comprises haemoglobin, white cell count (and differential), red cell count (and indices) and platelet count. Inflammation can cause increases in white cell and platelet populations. Mean cell volume (MCV) is used to classify anaemia into microcytic, normocytic or macrocytic.

Prothrombin time (PT) measurements help determine synthetic liver function. ${ }^{13} \mathrm{PT}$ is prolonged in patients treated with warfarin (INR may be reported in warfarin monitoring). Increases in PT can indicate vitamin $\mathrm{K}$ deficiency. ${ }^{14}$

Suggested monitoring frequency:

- BAPEN-white cell count 1-3 monthly, no mention of $\mathrm{PT}^{10}$

- NICE_full blood count and MCV_-guidance offers no distinction between inpatient/outpatient setting. ${ }^{2}$

- ESPEN (2020)—weekly or monthly, 3-4 monthly when stable. $^{11}$

- AuSPEN-'haematology screen' 3 monthly, with INR if anticoagulated $^{12}$

\section{Lipids: cholesterol and triglycerides}

Inflammation can cause decrease in concentration of cholesterol. ${ }^{6}$ Secondary hyperlipidaemia is a complication which can be associated with parenteral nutrition due to a variety of mechanisms. ${ }^{15}$ Raised concentrations of lipids should be confirmed on repeat measurement with triglyceride, high-density lipoprotein (HDL)cholesterol and non-HDL (or low-density lipoprotein (LDL))-cholesterol. LDL cholesterol is not routinely measured directly but is derived using the Friedewald formula (not valid if triglyceride is $>4.5 \mathrm{mmol} / \mathrm{L}$ ) LDL $=$ Total Cholesterol - HDL Cholesterol - (Triglycerides/2.2). ${ }^{16}$ Triglyceride concentration can increase twofold to threefold after a meal. ${ }^{14}$ Suggested monitoring frequency:

- BAPEN-3 monthly. ${ }^{10}$

- NICE-not given. ${ }^{2}$

- ESPEN (2020)—not given. ${ }^{11}$
- AuSPEN-'longer-term patients should have a lipid screening'-no frequency given. ${ }^{12}$

If patients who are HPN dependent are managed with lipid-free parenteral nutrition then testing for essential fatty acids might be appropriate, however, this is not routine practice.

\section{Vitamins}

Vitamin D

Vitamin $\mathrm{D}_{2}=$ ergocalciferol and vitamin $\mathrm{D} 3=$ cholecalciferol, assay detects the main storage form of vitamin D - 25OH-D2 and 25OH-D3, therefore, should request total $25-\mathrm{OH}$ vitamin D. 1-25 dihydroxy vitamin D is not routinely analysed. Inflammation can cause concentration decrease. ${ }^{17}$ Deficiency is defined as $25 \mathrm{OHD}<25 \mathrm{nmol} / \mathrm{L}$, possible insufficiency: $25-50 \mathrm{nmol} / \mathrm{L}$ and sufficiency: $>50 \mathrm{nmol} / \mathrm{L} .{ }^{18} \mathrm{Recom}-$ mendations on concentrations of vitamin $\mathrm{D}$ that indicate sufficiency or deficiency vary. Low calcium and elevated ALP may be the first indication of vitamin D deficiency. ${ }^{19}$ Suggested monitoring frequency:

$\checkmark$ BAPEN-3 monthly. ${ }^{10}$

$>$ NICE-6 monthly. ${ }^{2}$

- ESPEN (2020)—every 6-12 months. ${ }^{11}$

- AuSPEN-not given. ${ }^{12}$

- ACB-repeat after 3-6 months on replacement if baseline was low and potential absorption defect ${ }^{20}$.

Folate $\left(\mathrm{B}_{9}\right)$ and vitamin $\mathrm{B}_{12}$ (cyanocobalamin)

Serum concentration of folate indicates recent intake rather than tissue stores - red cell folate reflects whole body status however this is not routinely available. ${ }^{13} 19$ Deficiency of either is associated with megaloblastic anaemia (requires measurement of full blood count). Suggested monitoring frequency:

$\checkmark$ BAPEN-3 monthly. ${ }^{10}$

- NICE-guidance offers no distinction between inpatient/outpatient setting. ${ }^{2}$

- ESPEN (2020)—every 6-12 months. ${ }^{11}$

$\checkmark$ AuSPEN-not given. ${ }^{12}$

Vitamin $\mathrm{A}$ and vitamin $\mathrm{E}$

Limited testing availability of the assay requiring specialist laboratory, inflammation causes concentration decreases which can also occur if samples are not protected from light. ${ }^{5}$ Concentration does not provide ideal assessment of vitamin A status as serum concentration may not decline until liver stores have been critically depleted but low concentrations may be observed with adequate hepatic stores owing to decreased availability of binding proteins. Severe vitamin A deficiency can lead to night blindness. Vitamin A deficiency is also associated with vulnerability to measles and gastrointestinal or respiratory infections and may lead to anaemia (mechanism unknown). ${ }^{13}$ If serum lipids are elevated the results of vitamin $\mathrm{E}$ analysis are reported as a molar ratio (vitamin $\mathrm{E}$ is bound to lipoproteins). Vitamin $\mathrm{E}$ is involved in antioxidant and immune 
system defences and therefore deficiency may lead to impaired immunity. Deficiency can cause neuropathy and myopathy. ${ }^{14}$

Suggested monitoring frequency:

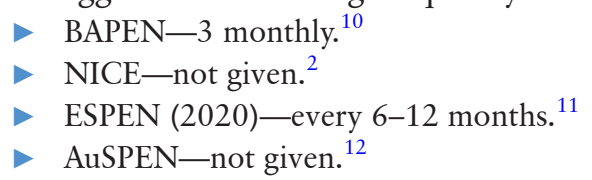

\section{Trace elements}

Iron and ferritin

Inflammation causes concentration of ferritin to increase and Fe concentration decreases. ${ }^{5}$ Large variation in reference intervals, due to different methods of analysis and large age and gender differences, however, intraindividual variation is small. ${ }^{6}$ Ferritin is the most useful indicator of iron deficiency-ferritin stores can be significantly decreased before any fall in iron occurs, a combination of chronic disease and iron deficiency may result in a normal ferritin concentration. In this situation, iron can be measured with transferrin and transferrin saturation to assist interpretation of iron status. Suggested monitoring frequency:

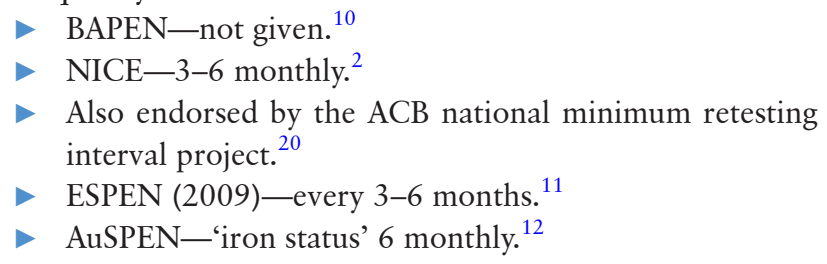

Zinc

Use trace element-free tube and transport to laboratory as soon as possible for rapid separation of serum from red blood cells. Serum concentrations do not accurately reflect whole body concentrations. ${ }^{16}$ There is limited testing availability requiring specialist laboratory, inflammation causes concentration decrease, as it is bound to albumin which is likely to be reduced..$^{5}$ If a patient has chronic inflammation and there is clinical concern about possible zinc deficiency then measurement might be appropriate with some adjustment made for low levels related to low albumin concentrations. High concentrations of copper or iron in the diet may decrease zinc intestinal absorption resulting in low serum zinc. Conversely, chronic ingestion of oral zinc supplements may induce reversible anaemia and leucopenia secondary to relative copper deficiency caused by reduced intestinal absorption. ${ }^{21}$ Zinc deficiency can cause perioral and perineal rash. ${ }^{14} 22$ Low concentrations can impair wound healing and cause diarrhoea. ${ }^{13} 14$ It can also cause a change in taste and some patients complain of food tasting of metal or cardboard. ${ }^{14}$ Deficiency can also lead to crinkly hair growth. ${ }^{14}$

Provision of adequate zinc intravenously to achieve a positive zinc balance is associated with improvement in nitrogen balance. ${ }^{13}$ Suggested monitoring frequency:

- BAPEN-3 monthly. ${ }^{10}$

- NICE-guidance offers no distinction between inpatient/outpatient setting. ${ }^{2}$
- ESPEN (2020)—every 6-12 months. ${ }^{11}$

- AuSPEN-6 monthly. ${ }^{12}$

Copper

Use serum trace element-free tube. There is limited testing availability requiring specialist laboratory, inflammation causes concentration increase. ${ }^{5}$ Copper deficiency can cause a microcytic anaemia (ie, unresponsive to iron therapy) and neutropaenia. ${ }^{21} 22$ Mainly biliary excretion so patients with cholestatic jaundice are at risk of copper accumulation. Copper deficiency can result from excess iron or zinc ingestion through interference with copper absorption. ${ }^{21}$ Suggested monitoring frequency:

- BAPEN-3 monthly. ${ }^{10}$

- NICE-guidance offers no distinction between inpatient/outpatient setting. ${ }^{2}$

- ESPEN (2020)-every 6-12 months. $^{11}$

$\rightarrow$ AuSPEN-6 monthly. ${ }^{12}$

\section{Manganese}

Use a whole blood sample trace element-free tube with ethylenediaminetetraacetic acid (EDTA) anticoagulant. Individual laboratories might request an empty EDTA tube is sent with the sample from the same batch to check for contamination. There is limited testing availability requiring specialist laboratory. Manganese is ubiquitous within the environment, including potentially in the metal needle used to withdraw blood, to reduce this potential for contamination the sample for trace element analysis should not be the first one taken. Inflammation does not affect concentrations. $^{23}$ Concentrations $>360 \mathrm{nmol} / \mathrm{L}$ indicates manganese retention. ${ }^{13} \mathrm{HPN}$ often contains a fixed combination of multivitamins and trace elements and tends to contain high concentrations of manganese which exposes long-term HPN patients to a risk of toxicity which can result in manganism (a parkinsonian-like neurodegenerative disorder). ${ }^{3414}$ Excretion is primarily via bile so accumulation can result if liver disease/cholestasis is present. ${ }^{13}$ Suggested monitoring frequency:

- BAPEN-3 monthly. ${ }^{10}$

$\rightarrow$ NICE-3-6 monthly. ${ }^{2}$

- ESPEN (2020)—annually. ${ }^{11}$

- AuSPEN-6 monthly. ${ }^{12}$

Selenium

Use a serum trace element-free tube and transport to lab as soon as possible for rapid separation of serum from red blood cells. There is limited testing availability requiring specialist laboratory. Inflammation causes concentration decrease. ${ }^{5}$ Toxicity may occur with concentrations $>5.1$ $\mu \mathrm{mol} / \mathrm{L} .{ }^{13}$ Serum concentration reflects recent intake, red cell glutathione peroxidase is a superior index of longterm intake but is not the preferred procedure in routine laboratories. ${ }^{13} 21$ Selenium is an important component of enzymes involved in antioxidant functions, thyroid hormone metabolism and male fertility. Selenium deficiency may contribute to cardiomyopathy, hypothyroidism and an impaired immune system. Excessive provision may 
result in hair loss, 'garlic breath', nail changes and peripheral neuropathy. ${ }^{14} 24$

Suggested monitoring frequency:

- BAPEN-3 monthly. ${ }^{10}$

- NICE-'Further testing dependent on baseline'. ${ }^{2}$

- ESPEN (2020)—every 6-12 months. ${ }^{11}$

- AuSPEN—6 monthly. ${ }^{12}$

\section{Chromium}

This is needed for pancreatic function and is not routinely measured.

\section{lodine}

This is not routinely measured however sufficient amount is necessary for normal thyroid function and so annual thyroid function tests (eg, with thyroid stimulating hormone) would be appropriate.

\section{Urinary sodium}

Random urinary sodium concentration is useful for determining hydration and sodium balance. It is most useful in jejunostomy patients or patients with a high output stoma or fistula, see above.

Patients with a jejunum in continuity with a functioning colon should have annual 24 hours urinary oxalate excretion measured as this can predict those likely to develop calcium oxalate renal stones which can be prevented with treatment.

Correction notice This article has been corrected since it published Online First. The title has been amended.

Acknowledgements Many thanks to those members of the BIFA committee who reviewed the guidance: Jeremy Nightingale, Alison Young, Phil Stevens, Gerard Rafferty, Rhys Hewett, Simon Gabe, Trevor Smith, Michael Glynn, Jeremy Woodward, Simon Lal, Theodoric Wong, Ruth Newton, Alison Culkin, Kirstine Farrer, Carolyn Wheatley, Mia Small, Gordon Carlson.

Contributors GWM-S, CK, LG and NT conducted the literature search, analysed literature and wrote the article. GWM-S, CK, LG, CM, JN and NT drafted, edited and revised the manuscript. Members of the BIFA committee reviewed and approved the manuscript.

Funding The authors have not declared a specific grant for this research from any funding agency in the public, commercial or not-for-profit sectors.

Competing interests None declared.

Patient consent for publication Not required.

Provenance and peer review Not commissioned; externally peer reviewed.

\section{ORCID iD}

Gavin William Mercer-Smith http://orcid.org/0000-0002-56201157

\section{REFERENCES}

1 Wengler A, Micklewright A, Hébuterne X, et al. Monitoring of patients on home parenteral nutrition (HPN) in Europe: a questionnaire based study on monitoring practice in 42 centres. Clin Nutr 2006;25:693-700.
2 CG 32. Nutrition support for adults: oral nutrition support, enteral tube feeding and parenteral nutrition, 2006. Available: nice.org.uk/guidance/cg32

3 Kirk C, Gemmell L, Lamb CA, et al. Elevated WholeBlood Manganese Levels in Adult Patients Prescribed "Manganese-Free" Home Parenteral Nutrition. Nutr Clin Pract 2020;35:1138-42.

4 Btaiche IF, Carver PL, Welch KB. Dosing and monitoring of trace elements in long-term home parenteral nutrition patients. JPEN J Parenter Enteral Nutr 2011;35:736-47.

5 Galloway P, McMillan DC, Sattar N. Effect of the inflammatory response on trace element and vitamin status. Ann Clin Biochem 2000;37:289-97.

6 ACB - Analyte Monographs [Internet]. Available: http://www. acb.org.uk/whatwedo/science/AMALC.aspx

7 Sherman RA, Eisinger RP. The use (and misuse) of urinary sodium and chloride measurements. JAMA 1982;247:3121-

8 Boyanton BL, Blick KE. Stability studies of twentyfour analytes in human plasma and serum. Clin Chem 2002;48:2242-7.

9 Coppolino G, Nicotera R, Cernaro V, et al. Iron infusion and induced hypophosphatemia: the role of fibroblast growth factor-23. Ther Apher Dial 201910.1111/1744-9987.13435. [Epub ahead of print: 04 Sep 2019].

10 British Association for Parenteral and Enteral Nutrition. Parenteral Nutrition Monitoring [Internet], 2016. Available: https://www.bapen.org.uk/nutrition-support/parenteralnutrition/monitoring

11 Pironi L. ESPEN guideline on home parenteral nutrition. Clinical Nutrition.

12 Gillanders L, Angstmann K, Ball P, et al. AuSPEN clinical practice guideline for home parenteral nutrition patients in Australia and New Zealand. Nutrition 2008;24:998-1012.

13 Burtis CA, Bruns DE. Tietz Fundamentals of Clinical Chemistry and Molecular Diagnostics. In: Sawyer BG, ed. 7th edn. Elsevier, 2015.

14 Austin P, Stroud M. Prescribing adult intravenous nutrition. Pharmaceutical Press 2007.

15 Raman M, Almutairdi A, Mulesa L, et al. Parenteral nutrition and lipids. In: Nutrients. . vol. 9. MDPI AG, 2017: 9. 388.

16 Marshall W, Lapsley M, Day A. Clinical Biochemistry. In: Marshall W, Lapsley M, Day A, eds. Third. Churchill Livingstone, 2014.

17 Blaauw R, Osland E, Sriram K, et al. Parenteral provision of micronutrients to adult patients: an expert consensus paper. JPEN J Parenter Enteral Nutr 2019;43:S5-23.

18 Francis R, Aspray T, Fraser W. Vitamin D and bone health: a practical clinical guideline for patient management Royal osteoporosis Society. The Royal Osteoporosis Society 2020.

19 Gidden F, Shenkin A. Laboratory support of the clinical nutrition service. Clin Chem Lab Med 2000;38:693-714.

20 Lang T. National minimum re-testing interval project: a final report detailing consensus recommendations for minimum retesting intervals for use in clinical biochemistry 2013.

21 Ayling R, Marshall W. Nutrition and Laboratory Medicine. In: Harris B, Lapsley M, eds. ACB Venture Publications, 2007.

22 Fessler TA. Trace elements in parenteral nutrition: a practical guide for dosage and monitoring for adult patients. Nutr Clin Pract 2013;28:722-9.

23 Zemrani B, McCallum Z, Bines JE. Trace element provision in parenteral nutrition in children: one size does not fit all. Vol. 10, Nutrients. MDPI AG 2018.

24 Shenkin A. Selenium in intravenous nutrition. Gastroenterology 2009;137:S61-9. 